\title{
Synthesis and Characterization of [2-Oxo-2-(4-methyl)phenyl amino]ethylene Methacrylate-styrene Copolymers and Determination of Monomer Reactivity Ratios
}

\author{
İbrahim EROL ${ }^{\dagger}{ }^{\text {Fuat }}$ YAVUZ, ${ }^{*}$ and Mustafa DURGUN* \\ Department of Chemistry, Faculty of Arts and Science, University of Afyon Kocatepe, Afyon, Turkey \\ ${ }^{*}$ Department of Chemistry, Faculty of Arts and Science, Harran University, Şanluurfa, Turkey
}

(Received September 25, 2003; Accepted February 4, 2004)

\begin{abstract}
Some copolymers of [2-oxo-2-(4-methyl)phenyl amino]ethylene methacrylate (PEMA) with styrene (ST) have been prepared in the presence of benzoylperoxide (BPO) in 1,4-dioxane solvent at $65^{\circ} \mathrm{C}$. The copolymers have been characterized by Infrared, ${ }^{1} \mathrm{H}$ and ${ }^{13} \mathrm{C}$ NMR techniques. The percentages of PEMA and ST in the copolymers have been established by elemental analysis. The glass transition temperatures and thermal stability of copolymers were obtained and discussed. The monomer reactivity ratios of copolymerizations are calculated by using both Kelen-Tüdös and Fineman-Ross equations.

KEY WORDS Ethylene Methacrylate / Styrene / Monomer / Reactivity Ratios / Thermal Analysis /
\end{abstract}

Nowadays there exits a strong demand for "functional polymers" with very specific properties. In polymer science the improvement of the mechanical properties has been the center of interest for many years, but today special electrical and optical properties of polymers receive an increasing interest. Functional groups give the polymer structure special character, substantially different from the inherent properties of the basic polymer chain. ${ }^{1}$ In recent years, some comprehensive work has been published on functional monomers and their polymers. ${ }^{2-4}$ The effect of polymer structure on the reactivity and properties of reactive moieties is very important for the chemical modifications and for the eventual applications of reactive polymers. ${ }^{5-7}$ Functionalized polymers have wide applications for various biological and technological purposes. ${ }^{8,9}$

Knowledge of the copolymer composition is an important step in the evaluation of its utility. Copolymer composition and its distribution are dependent on the reactivity ratios. The most common mathematical model of copolymerization is based on finding the relationship between the composition of copolymers and the composition of the monomer feed in which the monomer reactivity ratios are the parameters to be determined. ${ }^{10,11}$ The calculation of the monomer reactivity ratios requires the mathematical treatment of experimental data on the compositions of copolymers and monomer feed mixtures.

In this article we report the synthesis of a new methacrylate monomer derived from the reaction of $\alpha$-chloro $N$-( $p$-methyl)phenyl acetamide with sodium methacrylate as well as its free-radical copolymerization behavior.

\section{EXPERIMENTAL}

\section{Materials}

$P$-Toluidine and chloroacetylchloride (MERCK \& Co., INC.) were used as received. Ethanol, methanol, chloroform, $n$-hexane and benzene were freshly distilled over moleculer sieves prior to use. Formic acid, $n$-heptane, diethyl ether, triethylamine, 1,4-dioxane, acetonitrile (MERCK \& Co., INC.) and sodium methacrylate (Aldrich Chemical Company, Inc) were used as received. Styrene (ST) was freed from inhibitor by washing with $5 \% \mathrm{NaOH}$ solution followed by distilled water, drying over anhydrous $\mathrm{MgSO}_{4}$, and distillation under vacuum. Benzoyl peroxide (BPO) was recrystallized from a chloroform-methanol mixture.

\section{Monomer Synthesis}

The first $\mathrm{N}$-(4-methyl)phenyl chloroacetamide was prepared by reacting $p$-toluidine with chloroacetyl chloride using triethylamin. ${ }^{12}$ The monomer [2-oxo2-(4-methyl)phenyl amino]ethylene methacrylate was synthesized as follows: $1 \mathrm{~mol} \mathrm{~N}$-(4-methyl)phenyl chloroacetamide, $1.1 \mathrm{~mol}$ sodium methacrylate, $0.1 \mathrm{~mol}$ TEBAC and $0.1 \mathrm{~mol} \mathrm{NaI}$ as catalyst were stirred in $75 \mathrm{~mL}$ acetonitrile at $75-80^{\circ} \mathrm{C}$ in a reflux condenser for $24 \mathrm{~h}$. Then mixture was cooled, filtrated and evaporated. The resulting monomer purified by re-

${ }^{\dagger}$ To whom correspondence should be addressed (Tel: +90-272-2281311/103, Fax: +90-272-2281235, E-mail: iberol@ hotmail.com). 


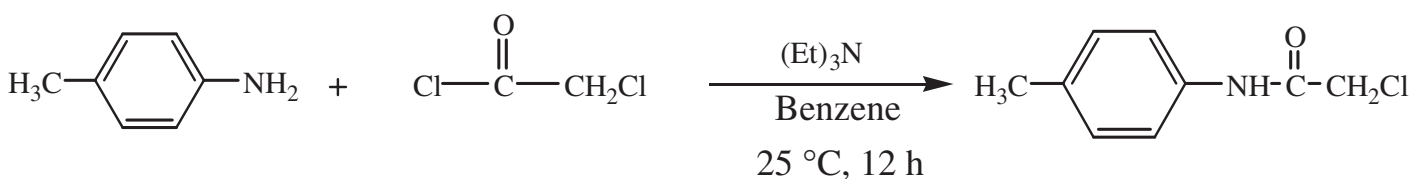

(I)<smiles>C=C(C)C(=O)ON=C(C)C(C(=O)OCC(=O)Nc1ccc(C)cc1)C(C)(C)C</smiles>

Scheme 1.

crystallization from ethanol (yield 75\%).

IR (KBr pellet), $\mathrm{cm}^{-1}: 3254$ (N-H stretching), 1680 $(\mathrm{C}=\mathrm{O}$ amide carbonyl $), 1726(\mathrm{C}=\mathrm{O}$ ester carbonyl $)$, $1630\left(-\mathrm{C}=\mathrm{CH}_{2}\right), 1255(\mathrm{C}-\mathrm{O}-\mathrm{C}), 3100(\mathrm{Ar}-\mathrm{H}), 2960$ (C-H aliphatic).

${ }^{1} \mathrm{HNMR}\left(\delta\right.$, ppm): 5.6 and $6.2\left(\underline{\mathrm{CH}}_{2}=\right.$ vinylic protons), $4.8\left(\mathrm{OCH}_{2}-\mathrm{C}=\mathrm{O}\right.$ protons $), 10.1(\mathrm{NH}-\mathrm{C}=\mathrm{O}$ protons), 7.2-7.5 (Âr- $\underline{\mathrm{H}}$ protons), 2.2 ( $\mathrm{Ar}-\underline{\mathrm{CH}}_{3}$ protons), $1.9\left(\mathrm{C}=\mathrm{C}-\underline{\mathrm{CH}}_{3}\right.$ protons $)$.

${ }^{13} \mathrm{C} \mathrm{NMR}(\delta, \mathrm{ppm}): 167$ (NH-C$=\mathrm{O}$ carbons), 169 $(\mathrm{O}=\mathrm{C}-\mathrm{O}$ carbons $), 18\left(\mathrm{CH}_{3}-\mathrm{C}=\mathrm{C}\right.$ methyl carbons $)$, $22\left(\mathrm{Ar}-\mathrm{CH}_{3}\right.$ carbons $), 64{ }^{-}\left(\mathrm{OCH}_{2}-\mathrm{C}=\mathrm{O}\right.$ carbons $)$, 120-130 (aromatic and $\mathrm{C}=\mathrm{C}$ carbons).

\section{Polymerization of the PEMA}

Poly(PEMA) was prepared by free radical polymerization of PEMA with 1\% BPO (total weight of monomer) in 1,4-dioxane solution (monomer/solvent, 1:4, $\mathrm{w} / \mathrm{v}$ ) in a sealed tube under nitrogen atmosphere at $65^{\circ} \mathrm{C}$ for $15 \mathrm{~h}$. with $90 \%$ conversion. The polymer was precipitated in excess ethanol. After a three reprecipitations from acetone solution using ethanol, the polymer was dried under vacuum at $40^{\circ} \mathrm{C}$ for $24 \mathrm{~h}$.

\section{Copolymerization}

The appropriate quantities of PEMA and ST in 1,4dioxane (monomer/solvent: $1 / 4 \mathrm{w} / \mathrm{v}$ ) and $\mathrm{BPO}$ $\left(\mathrm{Bz}_{2} \mathrm{O}_{2}\right)$ were placed in a standard reaction tube and the mixture was purged with nitrogen gas for deoxygenating. The tube was then tightly stoppered and maintained in a thermostatic oil bath at $65 \pm 1{ }^{\circ} \mathrm{C}$. The copolymerization was allowed to proceed for about $3-5 \mathrm{~h}$ to achieve a conversion of about $10 \%$. The polymerization mixture was then poured into ethanol and purified by at least two precipitations by ethanol from dichloromethane solution to ensure complete removal of unreacted monomers. The precipitated polymers were then filtrated, washed with the same precipitant and dried under vacuum at $45^{\circ} \mathrm{C}$ for $24 \mathrm{~h}$.

\section{Characterization Techniques}

Infrared Spectra were recorded by using a Perkin Elmer FTIR spectrometer. The ${ }^{1} \mathrm{H}$ and ${ }^{13} \mathrm{C}$ NMR spectra were run on a Bruker GmbH DPX-400 $400 \mathrm{MHz}$ FT-NMR spectrometer. Spectra were recorded at room temparature in DMSO- $d_{6}$ using TMS as internal standard. Elemental analysis were carried out by a Leco-932 microanalyzer. Thermal data were obtained by using a seteram instrument and a seteram thermobalance. Solubility parameters of the copolymers were estimated from the solubility test using 1,4-dioxane and non-solvents. The density of the polymers was determined by the flotation method.

\section{RESULTS AND DISCUSSION}

As shown in Scheme 1, we propose a new route for a new methacrylate ester having pendant amide moieties. The yields of the reactions in Scheme 1 are of medium quantity $(80 \%)$. The keto group was introduced into the amine by a Schotten-Baumann reaction with acyl halide using triethylamine catalyst. The esterification of sodium methacrylate with $\alpha$-chloro acetamide was also examined using TEBAC.

\section{Characterization of Monomer and Its Polymer}

The ${ }^{1} \mathrm{H}$ and ${ }^{13} \mathrm{CNMR}$ spectrums of the monomer are shown in Figure 1a,b. The ${ }^{1} \mathrm{H}$ and ${ }^{13} \mathrm{C}$ NMR spectra of the monomer has the characteristic peaks of the monomeric units. The main evidence of polymer formation is certainly the disappearance of some characteristic signals of the double band in the spectra, which was effectively observed in our case.

Thus, two bands vanished in the IR spectrum: the absorption band at $930 \mathrm{~cm}^{-1}$ assigned to the $\mathrm{C}-\mathrm{H}$ bending of geminal $=\mathrm{CH}_{2}$, and the stretching vibration band at $\mathrm{C}=\mathrm{C}$ at $1630 \mathrm{~cm}^{-1}$. From ${ }^{1} \mathrm{H}$ NMR spectroscopy the formation of the polymer is also clearly evident from the vanishing of the two singlets at 5.6 

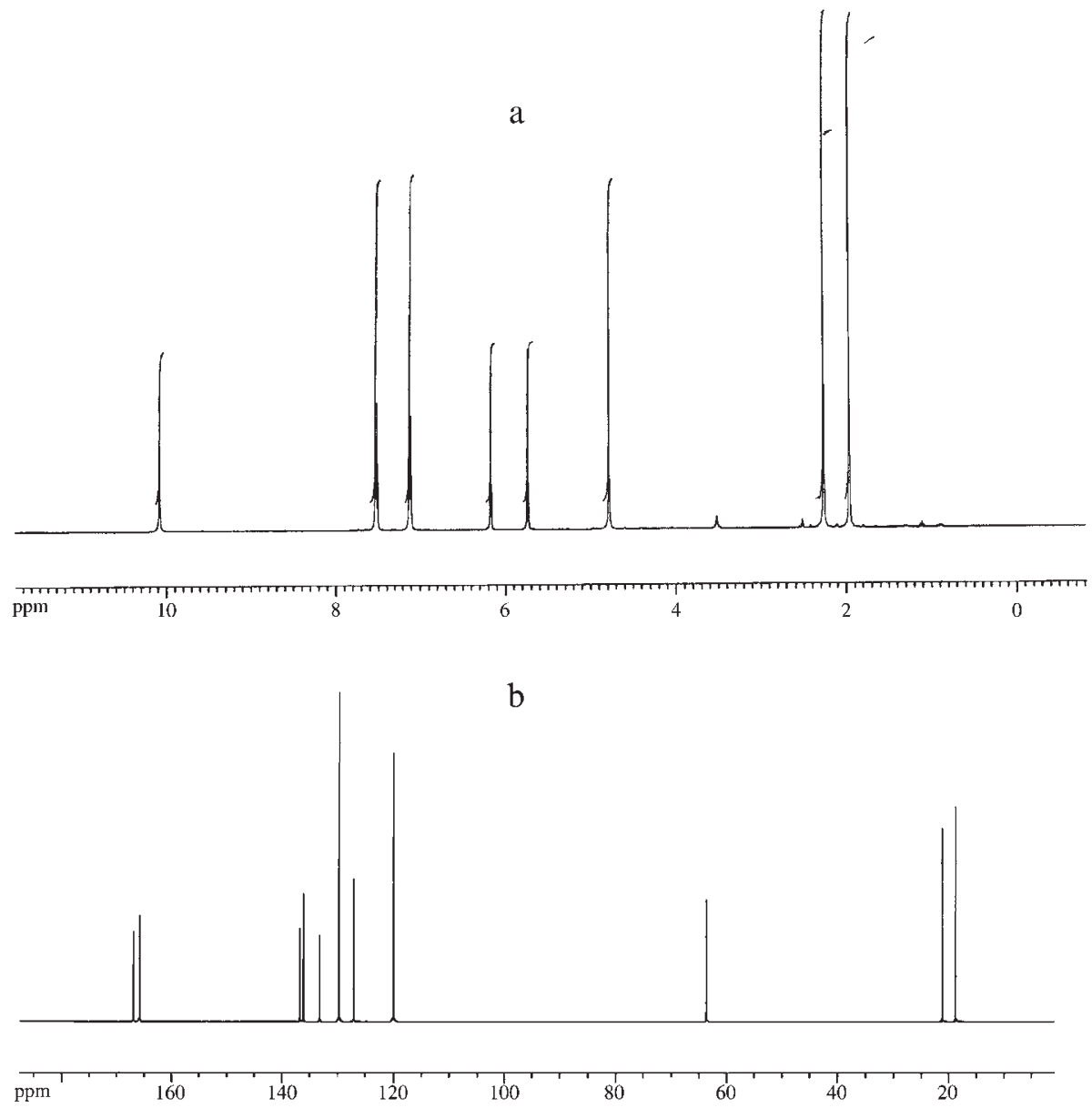

Figure 1. ${ }^{1} \mathrm{H} N M R$ (a) and ${ }^{13} \mathrm{C}$ NMR (b) spectrum of (PEMA) monomer.

Table I. Monomer compositions in feed and in copolymer ${ }^{\mathrm{a}}$

\begin{tabular}{|c|c|c|c|c|c|c|}
\hline \multirow[b]{2}{*}{$\begin{array}{c}\text { Sample } \\
\text { no. }\end{array}$} & \multicolumn{2}{|c|}{$\begin{array}{l}\text { Feed composition } \\
\text { in mole fraction }\end{array}$} & \multirow[b]{2}{*}{$\begin{array}{c}\text { Conversion } \\
(\%)\end{array}$} & \multirow[b]{2}{*}{$\begin{array}{c}\text { Elemental } \\
N \%\end{array}$} & \multicolumn{2}{|c|}{$\begin{array}{l}\text { Copolymer composition } \\
\text { in mole fraction }\end{array}$} \\
\hline & PEMA $\left(M_{1}\right)$ & ST $\left(M_{2}\right)$ & & & PEMA $\left(m_{1}\right)$ & $\mathrm{ST}\left(m_{2}\right)$ \\
\hline 1 & 0.250 & 0.750 & 7.510 & 2.910 & 0.296 & 0.704 \\
\hline 2 & 0.400 & 0.600 & 9.301 & 3.770 & 0.432 & 0.568 \\
\hline 3 & 0.500 & 0.500 & 11.217 & 4.160 & 0.505 & 0.495 \\
\hline 4 & 0.650 & 0.350 & 8.408 & 4.610 & 0.599 & 0.401 \\
\hline 5 & 0.800 & 0.200 & 9.103 & 5.060 & 0.708 & 0.292 \\
\hline
\end{tabular}

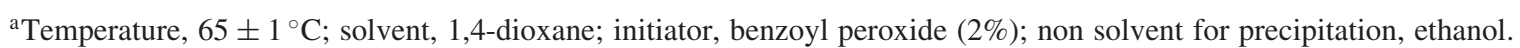

and $6.2 \mathrm{ppm}$ of the vinyl protons and the appearance of the broad signal at 1.3-1.4 ppm, assigned to an aliphatic $-\mathrm{CH}_{2}$-group. All the other spectroscopic signals for the macromolecule appeared in a normal mode.

\section{Characterization of the Copolymer}

Five new copolymers of PEMA-co-ST having different copolymer composition were prepared according to the experimental details given in Table I, using $\mathrm{BPO}$ as initiator in 1,4-dioxane solution under nitrogen atmosphere. The formula of poly(PEMA-co-ST) is illustrated in Scheme 2.<smiles>CCCC(C)(CC([Al-])c1ccccc1)C(=O)OCC(=O)Nc1ccc(C)cc1</smiles>

PEMA units 


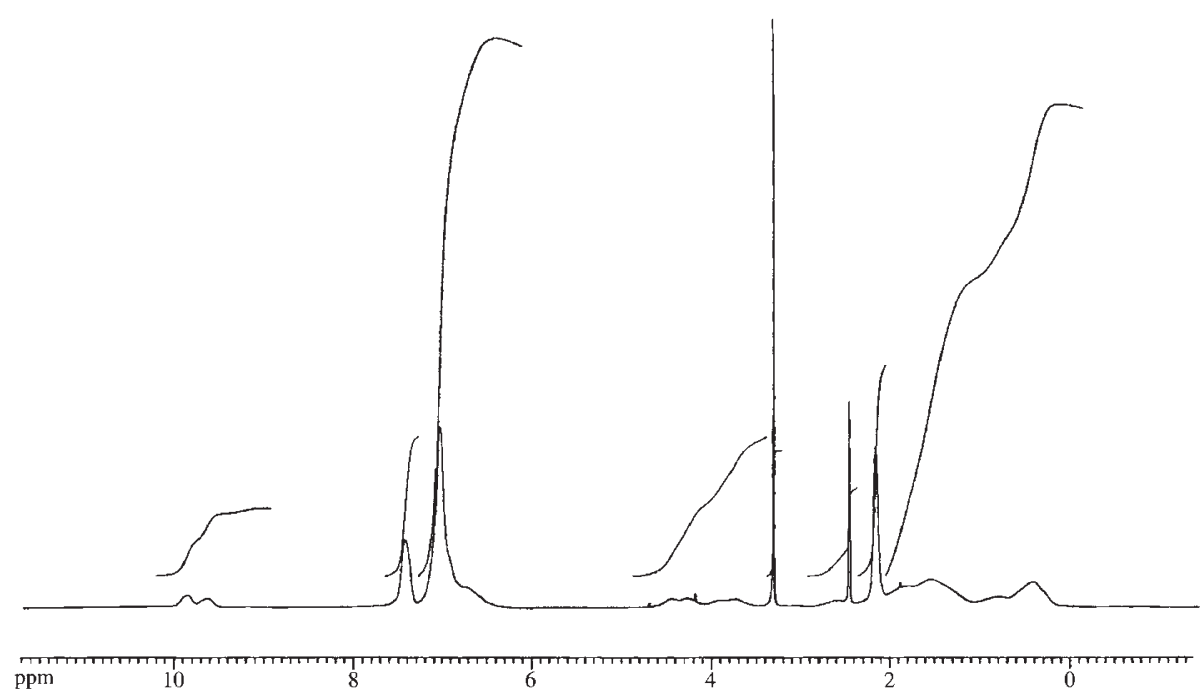

Figure 2. ${ }^{1} \mathrm{H}$ NMR spectrum of poly(PEMA-co-ST) (PEMA: 50.5 by mole\%).

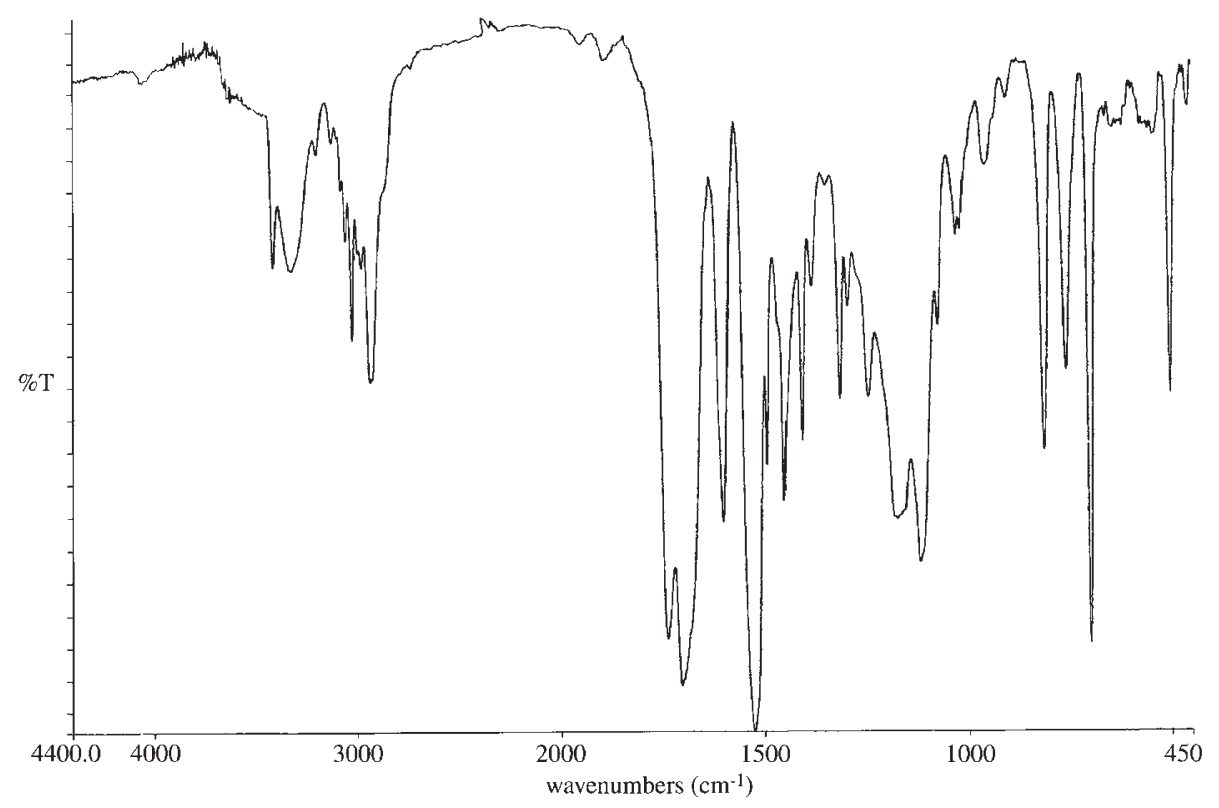

Figure 3. Infrared spectrum of poly(PEMA-co-ST) (PEMA: 50.5 by mole\%).

The FTIR spectrum of poly(PEMA-co-ST) is shown in Figure 3. The amide and ester carbonyl groups of the PEMA unit have sharp bands at 1680 and $1736 \mathrm{~cm}^{-1}$ respectively. The bands at 3000 3100 and $1595 \mathrm{~cm}^{-1}$ (Aromatic) show the characteristic for ST and PEMA. The N-H stretching bands for PEMA was at $3250 \mathrm{~cm}^{-1}$. The ${ }^{1} \mathrm{HNMR}$ spectra of the copolymers have the characteristic peaks of the monomeric units. The ${ }^{1} \mathrm{HNMR}$ spectra (Figure 2) of poly(PEMA-co-ST) show resonances at 7.2-7.5 ppm corresponding to the phenyl ring protons. The signals at $4.4 \mathrm{ppm}$ are a result of the $\mathrm{OCH}_{2}$ group of PEMA. The signals of $-\mathrm{CH}_{2}$ and $-\mathrm{CH}$ protons in the backbone are between 1.2-1.6 ppm. The $\mathrm{N}-\mathrm{H}$ protons of PEMA units are shown at $9.8 \mathrm{ppm}$.
Copolymer Composition and Monomer Reactivity Ratios

The compositions of the poly(PEMA-co-ST) samples were determined by elemental analysis. The monomer reactivity ratios of PEMA and ST were estimated by graphical methods according to the FinemanRoss $^{13}$ equation and the Kelen-Tüdös ${ }^{14,15}$ equation.

$$
\begin{aligned}
& G=r_{1} F-r_{2} \\
& \eta=\left(r_{1}+r_{2} / \alpha\right) \varepsilon-r_{2} / \alpha
\end{aligned}
$$

Here $\eta=G /(\alpha+F), \varepsilon=F /(\alpha+F), G=x(y-1) / x$, $F=x^{2} / y, \quad x=M_{1} / M_{2}, y=m_{1} / m_{2}$ and $\alpha=\left(F_{\max } \cdot\right.$ $\left.F_{\text {min }}\right)^{1 / 2}$.

$M_{1}$ is the mole fraction of PEMA in the feed, $M_{2}$ is the mole fraction of ST in the feed, $r_{1}$ is the reactivity 
Table II. The Finemann-Ross and Kelen-Tüdös parameters for copolymerization of PEMA with ST

\begin{tabular}{ccccccc}
\hline Sample no. & $X=M_{1} / M_{2}$ & $Y=m_{1} / m_{2}$ & $G=x(y-1) / y$ & $F=x^{2} / y$ & $\eta=G /(\alpha+F)$ & $\varepsilon=F /(\alpha+F)$ \\
\hline 1 & 0.333 & 0.420 & -0.459 & 0.264 & -0.281 & 0.166 \\
2 & 0.666 & 0.759 & -0.211 & 0.584 & -0.110 & 0.306 \\
3 & 1.000 & 1.020 & 0.019 & 0.980 & 0.008 & 0.426 \\
4 & 1.857 & 1.495 & 0.614 & 2.306 & 0.169 & 0.635 \\
5 & 4.000 & 2.422 & 2.348 & 6.606 & 0.296 & 0.833 \\
\hline
\end{tabular}

$\alpha=\sqrt{F_{\max } \cdot F_{\min }}=1.320$

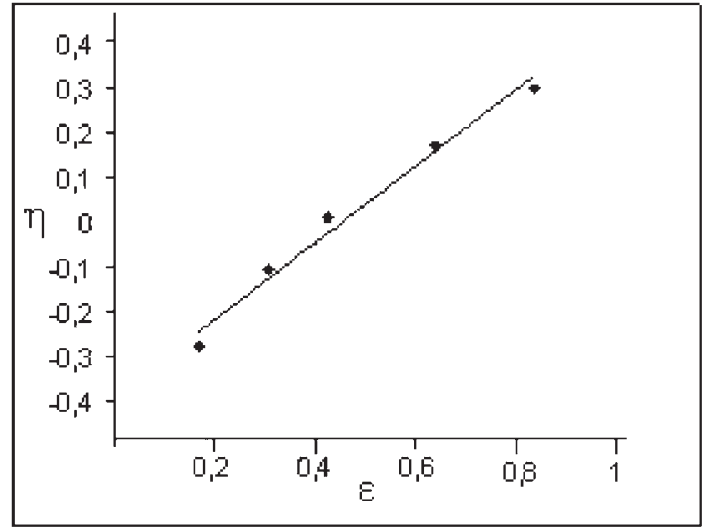

Figure 4. K-T plot for the determination of reactivity ratios of PEMA-ST copolymer system.

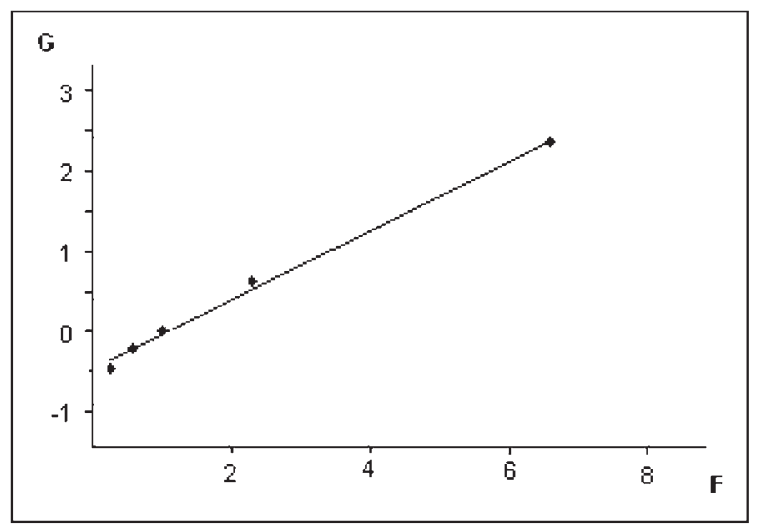

Figure 5. F-R plot for the determination of reactivity ratios of PEMA-ST copolymer system.

ratio of PEMA and $r_{2}$ is the reactivity ratio of ST. Kelen-Tüdös and Fineman-Ross parameters were calculated from the above equations using the data in Table II. Typical plots are shown in Figure 4 and 5, respectively. The following values were found: $r_{1}=$ $0.43 \pm 0.080, \quad r_{2}=0.46 \pm 0.015 \quad$ (Fineman-Ross); $r_{1}=0.46 \pm 0.003, r_{2}=0.51 \pm 0.075$ (Kelen-Tüdös). The monomer reactivity ratios $\left(r_{1}\right.$ and $\left.r_{2}\right)$ of poly(PEMA-co-ST) are less than 1 . This indicates that the system copolymerizes statistically. Comparing PEMA to ST, it should be stated that two monomers show similar copolymerization behavior. The reactivities of these monomers are close together.

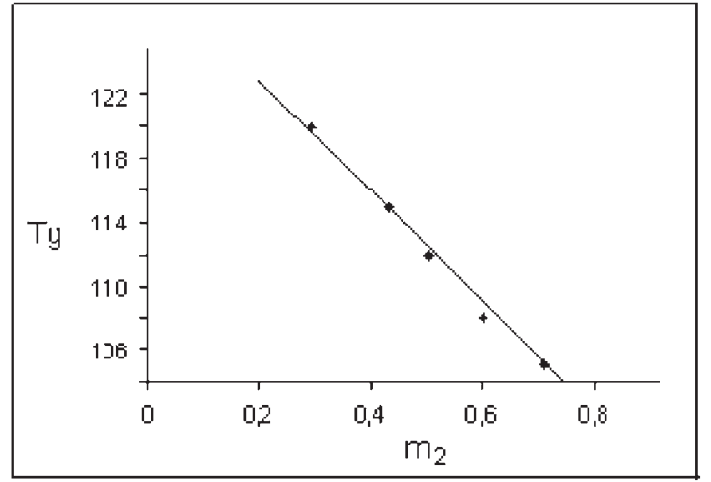

Figure 6. Dependence of $T_{\mathrm{g}}$ on mole fraction of ST in copolymer $\left(m_{2}\right)$, by DSC.

The $r_{1} \cdot r_{2}$ value indicates that the system copolymerizes statistically in the polymer chain, although there is a possible tendency for alternation. Thus, the factors, general reactivity and alternating tenden$\mathrm{cy}$, are predominant in determining the behavior of monomers in copolymerization.

\section{Thermal Analysis}

Differential scanning calorimetry (DSC) was performed at a heating rate of $20^{\circ} \mathrm{C} / \mathrm{min}$ under nitrogen atmosphere. A plot of copolymer composition versus glass transition temperature of the copolymer is shown in Figure 6. $T_{\mathrm{g}}$ values of poly(PEMA) and poly(ST) obtained under the same conditions with the copolymers were found to be 125 and $103^{\circ} \mathrm{C}$ respectively. The $T_{\mathrm{g}}$ values of all the copolymers were between those of the homopolymers of the same monomers, which is predicted by the dotted line in Figure 6. When the mole fraction of PEMA in the copoly(PEMA-co-ST) changed from 0.708 to 0.296 . The $T_{\mathrm{g}}$ value changed from 105 to $120^{\circ} \mathrm{C}$. The chain flexibility of poly ST was lower than that of poly PEMA. This means that the free volume in poly ST was higher than that in poly PEMA. The $p$-methyl phenyl group on the (PEMA) was caused diminution of the free volume for poly(PEMA). Therefore, an increase of $T_{\mathrm{g}}$ as a function of the number of PEMA units in the copolymer is an expected result.

The thermal stability of the copolymers was studied by programmed thermogravimetric analysis over a 


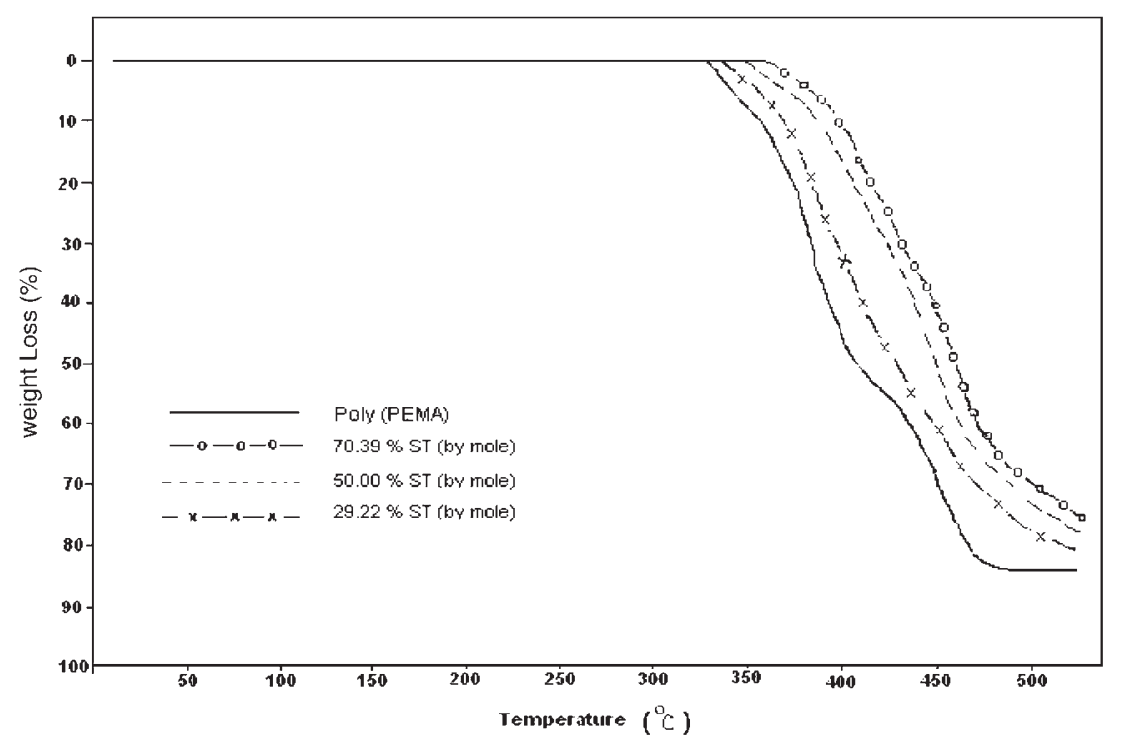

Figure 7. TGA curves of the polymer and copolymers heated in nitrogen at a heating rate of $20^{\circ} \mathrm{C} / \mathrm{min}$.

Table III. Some TGA result of the copolymers

\begin{tabular}{|c|c|c|c|c|c|}
\hline \multirow{2}{*}{ Polymer } & \multirow{2}{*}{ IDT $^{\mathrm{a}}$} & \multicolumn{3}{|c|}{ The temperature for a weight loss $(\%)$ of } & \multirow{2}{*}{$\begin{array}{c}\text { The residue }(\%) \\
\text { at } 450{ }^{\circ} \mathrm{C}\end{array}$} \\
\hline & & 20 & 50 & 70 & \\
\hline Poly(PEMA) & 310 & 360 & 407 & 450 & 28 \\
\hline Poly(ST) & 355 & 380 & 400 & 450 & 2 \\
\hline \multicolumn{6}{|c|}{ Poly(PEMA-co-ST) } \\
\hline$(29.6 / 70.4)$ & 352 & 411 & 460 & 498 & 55 \\
\hline$(50.5 / 49.5)$ & 348 & 403 & 449 & 490 & 50 \\
\hline$(70.8 / 29.2)$ & 340 & 355 & 435 & 460 & 35 \\
\hline
\end{tabular}

${ }^{\mathrm{a}}$ Initial decomposition temperature

temperature range from room temperature to $500^{\circ} \mathrm{C}$ under nitrogen atmosphere. Typical thermograms obtained by plotting percentage of residual weight against temperature for poly(PEMA) and three poly(PEMA-co-ST)'s are given in Figure 7. The thermal analysis data show that initial decomposition temperature (IDT) increases with the introduction of ST units. The IDT of poly(PEMA) and poly(ST) are 310 and $355^{\circ} \mathrm{C}$ respectively. Some degradation characteristics of the copolymers are given in Table III by comparison with those of the given homopolymers. The thermal stabilities of copolymers are between those of the corresponding homopolymers.

\section{Physical Parameters}

Some physical parameters such as density $(d)$, solubility parameters $(\delta)$, and inherent viscosity $\left(\eta_{\text {inh }}\right)$ of the polymers were determined in the study. The density of the polymers was determined experimentally by the flotation method ${ }^{16}$ at $25^{\circ} \mathrm{C}$ using mixtures of methanol and formic acid as the floating agent, and many glass beads of known densities. The solubility parameters of the polymers were determined by using a titration method ${ }^{16}$ at $25^{\circ} \mathrm{C}$ from a solubility test using 1,4-dioxane as solvent and $n$-heptane and ethanol
Table IV. Some physical parameters of polymers

\begin{tabular}{lccc}
\hline \multicolumn{1}{c}{ Sample } & $\begin{array}{c}d \\
\left(\mathrm{~g} / \mathrm{cm}^{3}\right)\end{array}$ & $\begin{array}{c}\eta_{\text {inh }} \\
(\mathrm{dl} / \mathrm{g})\end{array}$ & $\begin{array}{c}\delta \\
\left(\mathrm{cal} / \mathrm{cm}^{3}\right)\end{array}$ \\
\hline Poly(PEMA) & 1.135 & 0.534 & 11.280 \\
Poly(ST) & 1.047 & 0.612 & 9.500 \\
29.6\% PEMA (by mole) & 1.057 & 0.591 & 9.818 \\
50.5\% PEMA (by mole) & 1.073 & 0.567 & 10.311 \\
70.8\% PEMA (by mole) & 1.092 & 0.543 & 10.938 \\
\hline
\end{tabular}

as non-solvent. The inherent viscosities of $1 \%(\mathrm{w} / \mathrm{v})$ solutions of the polymers in 1,4-dioxane were determined at $30^{\circ} \mathrm{C}$ using an ubbelohde viscometer.

These values are shown in Table IV. The solubility parameter and density values of the copolymers were between those of the homopolymers. These values were influenced by their composition.

\section{CONCLUSIONS}

New methacrylate monomer (PEMA) having pendant amide moiety was synthesized and characterized by IR, ${ }^{1} \mathrm{H}$ and ${ }^{13} \mathrm{C}$ NMR. Copolymers of PEMA with ST were prepared using BPO as an initiator in 1,4-dioxane solution at $65^{\circ} \mathrm{C}$. IR, ${ }^{1} \mathrm{H}$ and ${ }^{13} \mathrm{C}$ NMR spectroscopies revealed the presence of monomeric con- 
stituents in the copolymers. Thermal stabilities and $T_{\mathrm{g}}$ 's of the copolymers were between those of the corresponding homopolymers. The monomer reactivity ratios in the copolymerization of PEMA with ST are less than unity, indicating a tendency for the monomer units to attract in the copolymers.

Acknowledgment. The authors wish to thank The Harran Universty Research Fund for support to this project (HÜBAK-510).

\section{REFERENCES}

1. O. Vogl, J. Macromol. Sci., Part A: Pure Appl. Chem., 33, 963 (1996).

2. R. Arshady, J. Macromol. Sci., Part C: Rev. Macromol. Chem. Phys., 32, 101 (1992).

3. I. Erol and C. Soykan, J. Macromol. Sci., Part A: Pure Appl. Chem., 39, 405 (2002).

4. N. Biçak and B. F. Senkal, React. Funct. Polym., 29, 123 (1996).
5. A. Akelah and D. C. Sherrington, Polymer, 24, 1369 (1983).

6. A. Akelah and A. Moet, Eds., "Reactive Functionalized Polymers, Synthesis, Properties and Applications," Chapman and Hall, London, 1988.

7. A. Akelah, J. Chem. Tech. Biotechnol. A, 34, 263 (1984).

8. A. Akelah, M. Hassanein, A. Selim, and E. R. Kebawy, Eur. Polym. J., 22, 983 (1986).

9. O. Vogl, A. C. Albertsson, and Z. Janovic, Polymer, 26, 1288 (1985).

10. R. Arshady, G. W. Kenner, and A. Ledwith, J. Polym. Sci., Polym. Chem. Ed., 12, 2017 (1974).

11. G. Ham, "Copolymerization, High Polymers," Vol 18, Interscience, New York, N.Y., 1964.

12. N. P. Peet, S. Sunder, and R. J. Barbuch, J. Heterocycl. Chem., 19, 747 (1982).

13. N. Fineman and S. D. Ross, J. Polym. Sci., 5, 259 (1950).

14. T. Kelen and F. Tüdös, J. Macromol. Sci. Chem. A, 9, 1 (1975).

15. T. Kelen, F. Tüdös, and S. Turcansyl, Polym. Bull., 2, 71 (1980).

16. E. L. McCafferty, "Laboratory Preparation for Macromolecular Chemistry,” McGraw-Hill, New York, N.Y., 1970, p 22. 